\title{
Benefits of an accident and emergency short stay ward in the staged hospital care of elderly patients
}

\author{
S A Khan, H Millington, F G Miskelly
}

\begin{abstract}
Objective-To study the potential of a short stay ward attached to an accident and emergency (A\&E) department to improve care and reduce admissions to hospital by enabling elderly patients to be monitored closely for up to $24 \mathrm{~h}$ before being formally admitted to hospital or discharged home. Patients admitted to the short stay ward were those who appeared to need only a brief period of assessment or treatment.

Methods-The medical records of all patients aged 65 years and above admitted to the short stay ward over a nine month period (April to December 1993, inclusive) were reviewed.

Results-13\% of all the patients over 65 attending $A \& E$ were admitted to the $A \& E$ ward. Of patients over 65 who were admitted to hospital, $20 \%$ were first admitted to the A\&E ward. There were 502 admissions to the short stay ward of patients aged 65 years and above, who constituted $38 \%$ of the total admissions to that ward. Admitting these selected patients to the short stay ward allowed $71 \%$ to be discharged home, usually within $24 \mathrm{~h}$, rather than being formally admitted to hospital.

Conclusions-The addition of a short stay ward can shorten the hospital stay for selected elderly patients and reduce the demand for inpatient hospital beds. This ward also improves the quality of care to elderly patients attending the A\&E department.

(F Accid Emerg Med 1997;14:151-152)
\end{abstract}

Keywords: elderly patients; short stay ward; accident and emergency department; hospital admission

Charing Cross

Hospital, London W6:

Department of

Medicine for the

Elderly

S A Khan

F G Miskelly

Department of Accident and Emergency

H Millington

Correspondence to: Dr F G Miskelly,

Department of Medicine for the Elderly, Charing Cross

Hospital, Fulham Palace

Road, London W6 8RF.

Accepted for publication 6 February 1997
Recent controversy has highlighted the crisis in accident and emergency (A\&E) departments over acute bed closures in London hospitals. ${ }^{1}$ One reason for this is because $A \& E$ departments are rapidly becoming major providers of primary care for elderly people. ${ }^{2}$ We studied the benefits of a short stay ward attached to an $A \& E$ department, and in particular the potential to improve care and reduce admissions by enabling elderly patients to be monitored closely for up to 24 hours before they are formally admitted to hospital or discharged home.

Our short stay ward has eight beds. Patients attending the $A \& E$ department who appeared to need only a brief period of assessment or treatment were admitted. All patients were assessed by the A\&E senior house officer (SHO), and where appropriate the registrar, before admission. The A\&E consultant or senior registrar, in conjunction with an SHO, reviewed all patients daily including weekends. Those patients requiring further hospital care were referred to the appropriate medical or surgical team. A few patients were admitted directly to the $A \& E$ ward by the medical or surgical teams.

The unit had a dedicated social worker, physiotherapist, and occupational therapist who assessed elderly patients each morning, Monday to Friday. At the weekend only urgent physiotherapy was available. For patients who had been discharged at the weekend, arrangements could be made for a community physiotherapist or occupational therapist to visit them at home on Monday. Social Services were prepared to take urgent referrals during the working week from the $A \& E$ ward, which they would not from the ordinary hospital wards. There was good liaison with the community social services, district nurses, community physiotherapist, community occupational therapists, and the London Ambulance Service.

\section{Methods}

The medical records of all patients aged 65 years and above admitted to the short stay ward over a nine month period (April to December 1993, inclusive) were reviewed. Thirteen per cent of all the patients aged over 65 attending $A \& E$ were admitted to the $A \& E$ ward. For patients over 65 who were admitted to hospital, $20 \%$ were first admitted to the A\&E ward. There were 502 admissions aged 65 years and above, who constituted $38 \%$ of the total admissions to the $\mathrm{A} \& \mathrm{E}$ ward. Of these, $37 \%$ were male and $63 \%$ female. Most $(98 \%)$ were in the age range 65 to 90 years, with a peak from 81 to 85 years. Of these 147 (29\%) were later admitted to the acute wards and $355(71 \%)$ were discharged home.

\section{Results}

The commonest reason for admission to the short stay ward was a fall or an injury secondary to poor mobility (45\%). Other reasons for admission are shown in table $1 .^{1}$ While on the ward, most patients $(61 \%)$ remained under the care of the A\&E team. Patients subsequently admitted to hospital from the short stay ward were admitted predominantly under the care of the medical department $(n=118 ; 80 \%)$, with a smaller percentage under the general surgeons and orthopaedic surgeons. Over $70 \%$ of 
Table 1 Diagnosis of patients on the short stay ward and subsequently discharged home or admitted to the hospital

\begin{tabular}{lccc}
\hline & $\begin{array}{l}\text { Admitted } \\
n=147(\%)\end{array}$ & $\begin{array}{l}\text { Discharged } \\
n=355(\%)\end{array}$ & $\begin{array}{l}\text { Total } \\
n=502(\%)\end{array}$ \\
\hline Falls and injury & $52(35 \%)$ & $171(48 \%)$ & $223(45 \%)$ \\
Infections & $22(15 \%)$ & $31(9 \%)$ & $53(11 \%)$ \\
Constipation & $7(5 \%)$ & $19(5 \%)$ & $26(5 \%)$ \\
Collapse & $9(6 \%)$ & $13(4 \%)$ & $22(4 \%)$ \\
Stroke/TIA & $4(3 \%)$ & $13(4 \%)$ & $17(3 \%)$ \\
Social & $3(2 \%)$ & $9(2 \%)$ & $12(2 \%)$ \\
Others & $50(34 \%)$ & $99(28 \%)$ & $149(30 \%)$ \\
\hline
\end{tabular}

TIA, transient ischaemic attack.

patients discharged from the short stay ward remained under the care of the $A \& E$ team. The majority of these patients $(87 \%)$ were discharged within 24 hours.

Hospital follow up appointments were arranged for $94(26 \%)$ of those patients discharged from the short stay ward. The remainder had follow up arranged with their general practitioner or with the community rehabilitation services.

\section{Discussion}

The staged hospital care of elderly patients is the basis of good medical practice. In our opinion not enough emphasis has been placed upon matching the facilities available in hospital with the patients' requirements. In the case of elderly patients a comparatively minor accident may seriously affect their ability to cope at home $^{3}$ and they frequently attend $A \& E$ for socioeconomic reasons ${ }^{2}$ rather than medical emergencies. In such circumstances patients may require only a brief admission for assessment and treatment. We found that admitting selected patients to the short stay ward allowed $71 \%$ to be discharged home, usually within 24 hours, rather than being formally admitted to hospital. Once admitted to the acute wards we believe they tend to remain in hospital much longer than otherwise necessary, if only because 48 hours notice is required to provide an ambulance. An ambulance can be arranged from the short stay ward without any notice.

Some elderly patients were admitted to the short stay ward for reasons other than assess- ment and treatment. These included patients with a diagnosis of imminent death. These patients and their relatives derived benefit from the comfort and privacy that would not have been available in a busy A\&E. The availability of a short stay ward probably also reduced the number of unnecessary admissions and the problem of overcrowding in the $A \& E$ department.

Factors which seemed to influence the successful discharge of patients from the short stay ward included: the availability of physiotherapy for assessment and treatment of poor mobility; rapid access to an occupational therapist to provide aids and adaptations; a dedicated A\&E social worker; and close liaison with the community social services, facilitating increased home care when required. The ambulance service often agreed to take patients home without prior notice and the daily consultant ward round added emphasis to the policy of rapid discharge.

Twenty six per cent of the patients were given hospital follow up arrangements after discharge and the remainder were referred to the community medical or paramedical services. Previous studies on elderly patients discharged from $A \& E$ have shown a high level of unmet need ${ }^{3}$ which has increased awareness by the $A \& E$ staff regarding follow up arrangements of elderly patients discharged home.

We conclude that the addition of a short stay ward can shorten the hospital stay for selected elderly patients and can have a significant impact on the demand for inpatient hospital beds. This ward also improves the quality of care to elderly patients attending the A\&E department.

\footnotetext{
1 House of Commons debate on acute bed closures in London hospitals. 10 May 1995.

2 Dove AF, Dave SH. Elderly patients in the accident department and their problems. BMJ 1986;292:808-9.

3 Currie CT, Lawson PM, Robertson CE, Jones A. Elderly patients discharged from an accident and emergency department-their dependency and support. Arch Emerg
} Med 1984;1:205-13. 